ARTICLE

\title{
Long-life Li/polysulphide batteries with high sulphur loading enabled by lightweight three-dimensional nitrogen/sulphur-codoped graphene sponge
}

\author{
Guangmin Zhou', Eunsu Paek², Gyeong S. Hwang ${ }^{2}$ \& Arumugam Manthiram
}

Lithium-sulphur batteries with a high theoretical energy density are regarded as promising energy storage devices for electric vehicles and large-scale electricity storage. However, the low active material utilization, low sulphur loading and poor cycling stability restrict their practical applications. Herein, we present an effective strategy to obtain Li/polysulphide batteries with high-energy density and long-cyclic life using three-dimensional nitrogen/ sulphur codoped graphene sponge electrodes. The nitrogen/sulphur codoped graphene sponge electrode provides enough space for a high sulphur loading, facilitates fast charge transfer and better immobilization of polysulphide ions. The hetero-doped nitrogen/sulphur sites are demonstrated to show strong binding energy and be capable of anchoring polysulphides based on first-principles calculations. As a result, a high specific capacity of $1,200 \mathrm{mAh}^{-1}$ at $0.2 \mathrm{C}$ rate, a high-rate capacity of $430 \mathrm{mAhg}^{-1}$ at $2 \mathrm{C}$ rate and excellent cycling stability for 500 cycles with $\sim 0.078 \%$ capacity decay per cycle are achieved.

\footnotetext{
${ }^{1}$ Materials Science and Engineering Program \& Texas Materials Institute, The University of Texas at Austin, 204 East Dean Keeton Street, Mail Stop: C2200 Austin, Texas 78712, USA. ${ }^{2}$ McKetta Department of Chemical Engineering, The University of Texas at Austin, 204 East Dean Keeton Street, Mail Stop: C2200, Austin, Texas 78712, USA. Correspondence and requests for materials should be addressed to A.M. (email: rmanth@mail.utexas.edu)
} 
A s energy storage devices, lithium-ion batteries (LIBs) play a dominant role in portable electronic devices due to their high performance compared with other battery systems ${ }^{1,2}$. However, the increased demand for electric vehicles and largescale smart grid stringently requires batteries with high-energy density, low cost and long cycle life ${ }^{3}$. The current main challenge is the capacity mismatch between the cathode and anode, which makes LIB approach its theoretical energy density limits ${ }^{4,5}$. The relatively lagged progress on cathodes becomes a barrier in further improving the energy density of LIBs, which has triggered the exploration of new electrochemical systems, such as the Lithium-sulphur (Li-S) batteries with a high theoretical energy density of $2,600 \mathrm{Wh} \mathrm{kg}^{-1}$ (refs 6,7). Despite the considerable advantages of Li-S battery, several problems prevent it from practical applications: (1) the insulating characteristic of sulphur and its discharge products $\left(\mathrm{Li}_{2} \mathrm{~S}\right)$, leading to a low utilization of active material; (2) large volumetric expansion/shrinkage (80\%) during discharge/charge, resulting in an instability of the electrode structure; (3) the soluble intermediates $\left(\mathrm{Li}_{2} \mathrm{~S}_{x}, 3 \leq x \leq 8\right)$ in the organic liquid electrolyte during the cycle process bring about the polysulphide 'shuttle effect', which leads to irreversible capacity loss and corrosion on the lithium-metal anode $e^{4,8,9}$.

Much effort has been devoted to solving these issues: improving the electrical conductivity of the sulphur electrode by integrating with carbon materials or conductive polymers ${ }^{8-14}$; designing yolk-shell structure with internal void space to accommodate the volume expansion of sulphur ${ }^{15,16}$; using novel electrolyte additives such as $\mathrm{P}_{2} \mathrm{~S}_{5}$ or $\mathrm{Cs}^{+}$to suppress the polysulphide shuttle and passivate the lithium-metal surface ${ }^{17,18}$; and modifying the surface chemistry of the hosts to prevent the shuttle effect of the soluble polysulphides between the cathode and the anode, enabling better cycle performance ${ }^{19-22}$. However, the areal loading of sulphur electrode in most of the reported work is $<2.0 \mathrm{mg} \mathrm{cm}^{-2}$ and the sulphur content in the electrode is $<70 \mathrm{wt}$. \%, which are not enough to satisfy the demands for high-energy density batteries $5,12,23-25$. Generally, conventional electrode requires the use of inactive materials such as conductive agents, metallic current collectors and binders, which will also offset the high-energy density advantage of Li-S batteries.

Moreover, flat current collectors face the challenge of increasing the electrode thickness due to the easy delamination of active materials and limitation in lithium diffusion kinetics. Therefore, three-dimensional (3D) battery electrode design has recently been explored as an effective way to enhance the energy per surface area of batteries ${ }^{26,27}$. For example, Miao et al. ${ }^{28}$ synthesized 3D carbon fibre cloth current collectors to host sulphur for achieving high sulphur loading and high areal capacity in Li-S batteries; Wu's group ${ }^{29}$ impregnated sulphur into a 3D graphene framework to increase the sulphur areal mass loading in the composite electrodes; Yuan et al. ${ }^{30}$ adopted a bottom-up strategy to fabricate 3D hierarchical free-standing carbon nanotube-S paper electrodes to improve the sulphur content; and Cheng's group ${ }^{31}$ reported flexible 3D graphene foams as the current collector to accommodate large amount of sulphur with high areal capacity. However, with the increase of sulphur loading, the internal sulphur is not easily accessible to the electrolytes and hard to be used rapidly, which leads to the phenomenon of 'sulphur activation' with lower capacity in the initial few cycles ${ }^{28,29,31}$. Therefore, a simpler and more effective way to enable high sulphur utilization, especially when sulphur loading is high, is still challenging while worth exploring.

Instead of adopting solid sulphur as the precursor followed by melt-diffusion or liquid infiltration methods, the dissolved lithium polysulphide systems have recently been proved to make active materials distribute more uniformly, improve sulphur utilization, alleviate electrode structure variation and facilitate the kinetics of the $\mathrm{Li}-\mathrm{S}$ redox reaction ${ }^{5,7,32-35}$. Taking the above discussion into consideration, we present the use of a lightweight, porous nitrogen- and sulphur- (abbreviated as N, S) codoped 3D graphene sponge as the additive/binder-free electrode structure to accommodate large amounts of dissolved lithium polysulphides. The active materials could reach as high as $4.6 \mathrm{mg} \mathrm{cm}^{-2}$ when the graphene sponge is employed as a $3 \mathrm{D}$ current collector. The interconnected graphene network facilitates fast electron and ion transfer. The sulphur and/or nitrogen doping could facilitate fast charge transfer, increase the affinity between the polysulphide species and the carbon-based framework, facilitate better immobilization of the polysulphide ions, and promote the $\mathrm{Li}_{2} \mathrm{~S} /$ polysulphide/S reversible conversion to improve the electrochemical performance of $\mathrm{Li}-\mathrm{S}$ batteries $19,21,22,36$. The combination of physical adsorption of lithium polysulphides onto porous graphene and the chemical binding of polysulphides to $\mathrm{N}$ and $\mathrm{S}$ sites in graphene suppresses sulphur loss during the discharge/charge processes, enabling a high specific capacity of $1,200 \mathrm{mAh} \mathrm{g}^{-1}$ at $0.2 \mathrm{C}$ rate, a high-rate capacity of $430 \mathrm{mAh} \mathrm{g}^{-1}$ at $2 \mathrm{C}$ rate and excellent cycling stability for 500 cycles with nearly $100 \%$ Coulombic efficiency for the $\mathrm{N}, \mathrm{S}$-codoped graphene electrode.

\section{Results}

Synthesis and characterization of graphene-based sponges. Figure 1a demonstrates the typical photographs of the as-prepared reduced graphene oxide (rGO), S-doped graphene, $\mathrm{N}$-doped graphene and $\mathrm{N}, \mathrm{S}$-codoped graphene sponges obtained by hydrothermal reaction using, respectively, $\mathrm{GO}, \mathrm{GO} / \mathrm{Na}_{2} \mathrm{~S}, \mathrm{GO} /$ urea and $\mathrm{GO} /$ thiourea as precursors followed by freeze-drying. $\mathrm{Na}_{2} \mathrm{~S}$, urea and thiourea were employed as sulphur, nitrogen and nitrogen/sulphur sources, as well as reducing agents for GO during the hydrothermal assembly process. After freeze-drying, the morphology of the samples was retained and no obvious shrinkage/expansion is observed. The size and shape of the graphene-based sponges can be adjusted by controlling the concentration of GO, reaction temperature and the volume/shape of the used autoclaves. The freeze-dried N,S-codoped graphene sponge is light and can stand stably on the top of a dandelion without deforming it at all (Fig. 1b), which makes it a good candidate as a lightweight $3 \mathrm{D}$ current collector. It can be cut and pressed into slices for direct use as a host for dissolved lithium polysulphides without metal current collectors, binders and conductive additives, and the sulphur/nitrogen doping in graphene is suggested to interact with lithium polysulphide $/ \mathrm{Li}_{2} \mathrm{~S}$ to improve the cycle stability of Li-S batteries, as illustrated in Fig. 1c.

Figure 2a and Supplementary Figure 1 show the typical scanning electron microscopy (SEM) images of the graphenebased sponges. The alkaline solution environment, when using $\mathrm{Na}_{2} \mathrm{~S}$ and urea as doping sources, is not beneficial for the formation of intact nitrogen- or sulphur-doped graphene sponges in a one-pot hydrothermal reaction due to the increased electrostatic repulsion between the rGO sheets ${ }^{37,38}$, so the synthesis of rGO sponge followed by sulphur and nitrogen doping strategy is adopted. Therefore, the rGO, S-doped graphene and $\mathrm{N}$-doped graphene sponges show quite similar morphologies (Supplementary Fig. 1a-c), displaying a relatively loose structure with large pores of tens of micrometres formed by linked graphene sheets. In contrast, the N,S-codoped graphene sponge cross-links to form a $3 \mathrm{D}$ interconnected network structure with rich pores in a smaller size of $2-8 \mu \mathrm{m}$ (Fig. $2 \mathrm{a}$ ). The macropores in the $3 \mathrm{D}$ hierarchical network structure allow efficient ion diffusion/mass transfer and could also be used as the buffering/absorption reservoir of polysulphides ${ }^{39,40}$. Scanning transmission EM 


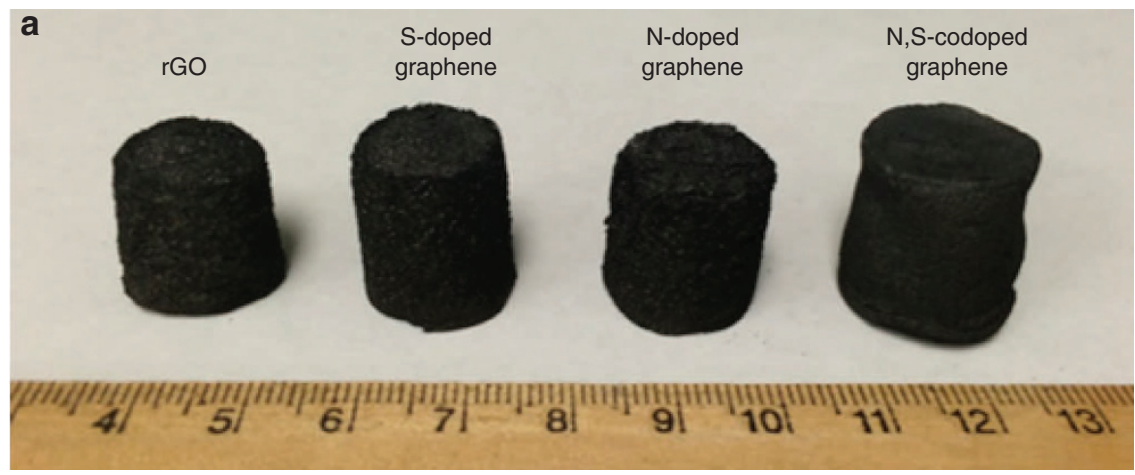

b

C

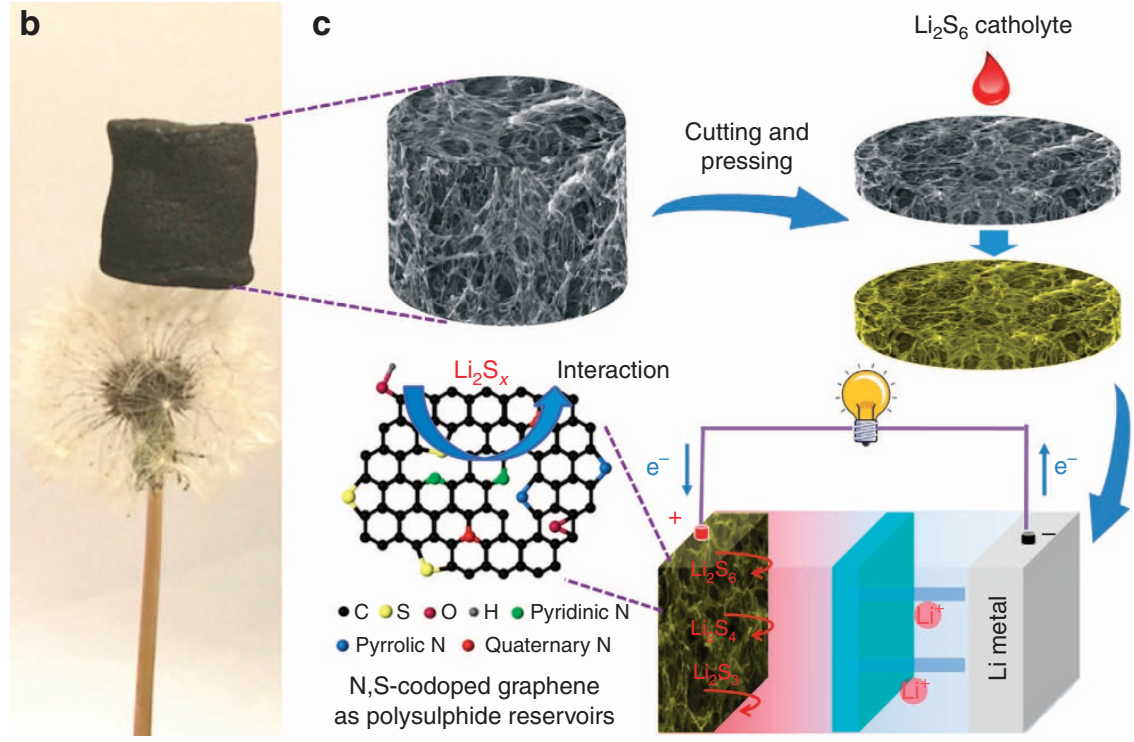

Figure 1 | Photographs of graphene sponges and schematic model of the assembled cell. (a) Photographs of the rGO, S-doped graphene, N-doped graphene and N,S-codoped graphene sponges after the hydrothermal reaction and freeze-drying. (b) A lightweight N,S-codoped graphene sponge standing on a dandelion. (c) Illustration of the formation process of the N,S-codoped graphene electrode and schematic of the fabrication of a Li/dissolved polysulphide cell with $\mathrm{N}, \mathrm{S}$-codoped graphene electrode after adding polysulphide catholyte.
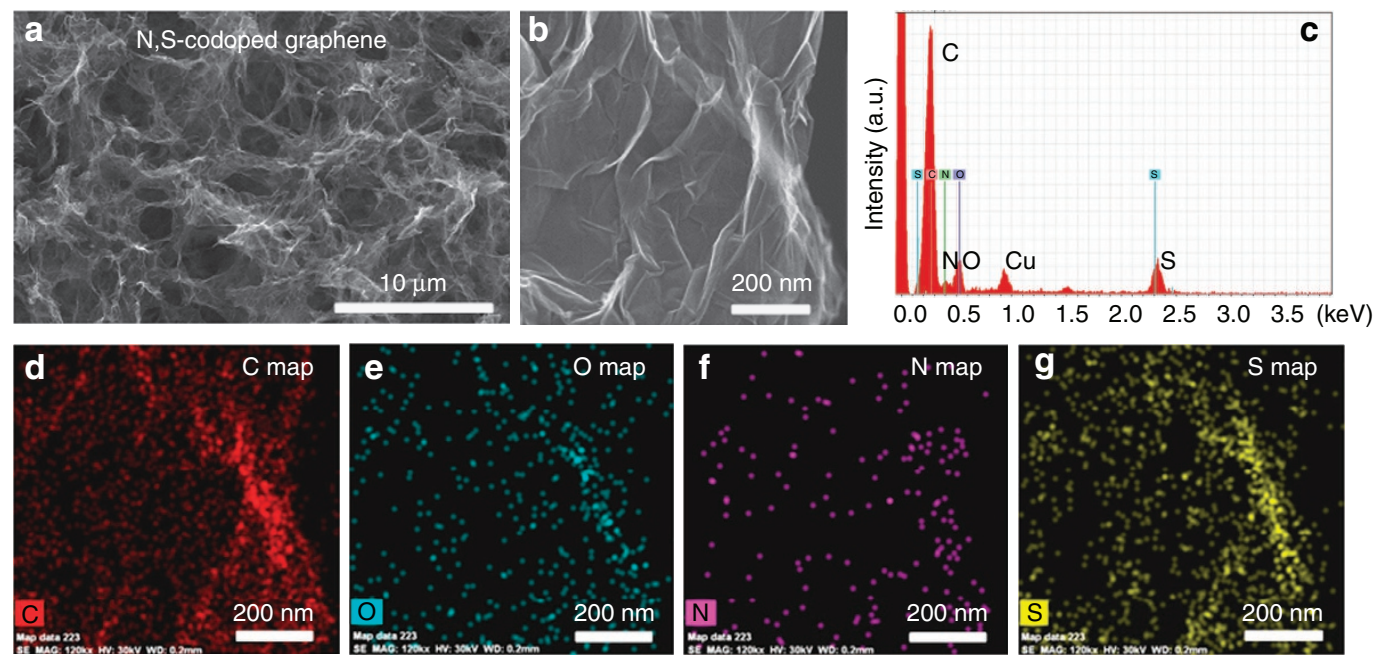

Figure 2 | Morphology and microstructure of the N,S-codoped graphene sponge. (a) SEM image of the N,S-codoped graphene sponge. (b) Highmagnification SEM image of the N,S-codoped graphene sponge. (c) EDS spectrum of the N,S-codoped graphene. (d) Carbon, (e) oxygen, (f) nitrogen and (g) sulphur elemental mappings of the $\mathrm{N}, \mathrm{S}$-codoped graphene in $\mathbf{b}$. 
(STEM) and high-magnification SEM characterizations reveal that the resultant N,S-codoped graphene sponge consists of wrinkled graphene sheets (Fig. 2b and Supplementary Fig. 2). $\mathrm{N}_{2}$ isothermal adsorption-desorption analysis (Supplementary Fig. 3, Supplementary Table 1) reveals that the BrunauerEmmmett-Teller specific surface areas of N,S-codoped graphene, $\mathrm{N}$-doped graphene and $\mathrm{S}$-doped graphene sponges are, respectively, $171.4 \mathrm{~m}^{2} \mathrm{~g}^{-1}, 136.7 \mathrm{~m}^{2} \mathrm{~g}^{-1}$ and $133.5 \mathrm{~m}^{2} \mathrm{~g}^{-1}$, which are slightly higher than that of the rGO sponge $\left(108.7 \mathrm{~m}^{2} \mathrm{~g}^{-1}\right)$. The $\mathrm{N}_{2}$ adsorption-desorption isotherms of all the graphene-based sponges show a main adsorption at a relative pressure $>0.9$ with a small hysteresis loop (Supplementary Fig. 3a), indicating the predominant meso/macropore structure, consistent with the pore size distributions (Supplementary Fig. 3b) and SEM/STEM observation (Fig. 2a, Supplementary Figs 1 and 2a). Energydispersive X-ray spectroscopy (EDS) reveals the presence of $\mathrm{C}, \mathrm{O}$, $\mathrm{Cu}$ (from $\mathrm{Cu}$ grid), $\mathrm{N}$ and $\mathrm{S}$ in the N,S-codoped graphene sponge (Fig. 2c), indicating the successfully incorporated N,S atoms into the carbon framework. The EDS elemental mapping further confirms the existence and homogeneous distribution of $\mathrm{C}, \mathrm{O}, \mathrm{N}$ and $\mathrm{S}$ on the surface of N,S-codoped graphene (Fig. $2 \mathrm{~d}-\mathrm{g}$ ). These functional groups are beneficial to restrict the polysulphides from escaping to the electrolyte, which will be discussed below.

The transformation from GO to the final graphene-based sponges was examined by X-ray diffraction (XRD) and Raman spectroscopy (Supplementary Fig. 4). GO shows the typical diffraction peak at $\sim 11^{\circ}$ (ref. 41). After the hydrothermal reaction, this peak disappears while a broad diffraction peak emerges between $18^{\circ}$ and $28^{\circ}$ in the XRD patterns for rGO, $\mathrm{S}$-doped graphene, $\mathrm{N}$-doped graphene and $\mathrm{N}, \mathrm{S}$-codoped graphene sponges, demonstrating the reduction of GO (Supplementary Fig. 4a). Moreover, this peak for the N,S-codoped graphene sponge is sharper and shifted to higher angles compared with that of rGO, S-doped graphene and $\mathrm{N}$-doped graphene sponges, suggesting the more efficient reduction process by $\mathrm{N}, \mathrm{S}$-doping. Raman spectra further provide additional evidence of the doping and reduction processes (Supplementary Fig. 4b). Two prominent peaks are observed at $1,365 \mathrm{~cm}^{-1}$ and $1,590 \mathrm{~cm}^{-1}$, corresponding to the characteristic $D$ and $G$ bands of carbon materials ${ }^{41}$, respectively. Generally, the intensity ratio of the $D$ band to $G$ band $\left(I_{\mathrm{D}} / I_{\mathrm{G}}\right)$ is used to evaluate the degree of defects in carbon materials, and a higher ratio indicates an increased amount of defects that is proportional to the extent of reduction ${ }^{41}$. Compared with $\mathrm{GO}\left(I_{\mathrm{D}} / I_{\mathrm{G}}=0.93\right)$, the $I_{\mathrm{D}} / I_{\mathrm{G}}$ ratio increases to $0.99,1.03,1.07$ and 1.16 for rGO, S-doped graphene, N-doped graphene and N,Scodoped graphene sponges, respectively, suggesting the removal of oxygen-containing groups and the insertion of heteroatoms into the graphene network with more structural defects ${ }^{42}$. The increased $I_{\mathrm{D}} / I_{\mathrm{G}}$ ratio is indicative of the enhanced reduction, which is in agreement with the electrical conductivity tests of these sponges (Supplementary Fig. 5).

The surface chemical composition and functional groups of the GO, rGO, S-doped graphene, N-doped graphene and N,Scodoped graphene were identified by X-ray photoelectron spectroscopy (XPS), as shown in Fig. 3. For GO and rGO, only $\mathrm{C} 1 \mathrm{~s}$ and $\mathrm{O} 1 \mathrm{~s}$ signals were detected in the XPS survey spectra. After nitrogen and nitrogen/sulphur doping, a new peak located at $\sim 400.5 \mathrm{eV}$ is observed in both the $\mathrm{N}$-doped graphene and N,Scodoped graphene, corresponding to $\mathrm{N} 1 \mathrm{~s}^{43}$; two other peaks appearing at 164.5 and $228.2 \mathrm{eV}$ for S-doped graphene and N,S-codoped graphene are attributed to S 2 p and S 2 s (Fig. 3a), respectively, suggesting the efficient $\mathrm{S}$-doping in graphene. The elemental contents in these samples are summarized in Supplementary Table 2. The nitrogen contents in the $\mathrm{N}$-doped a

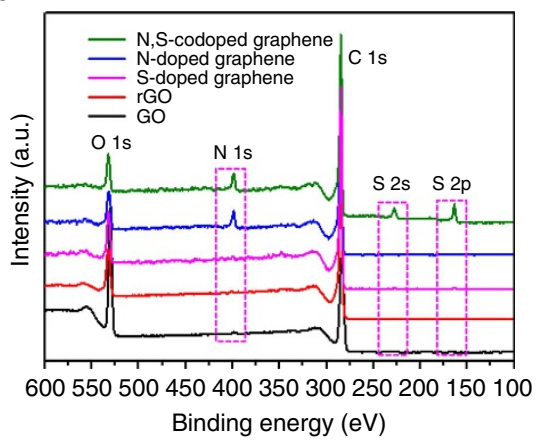

b
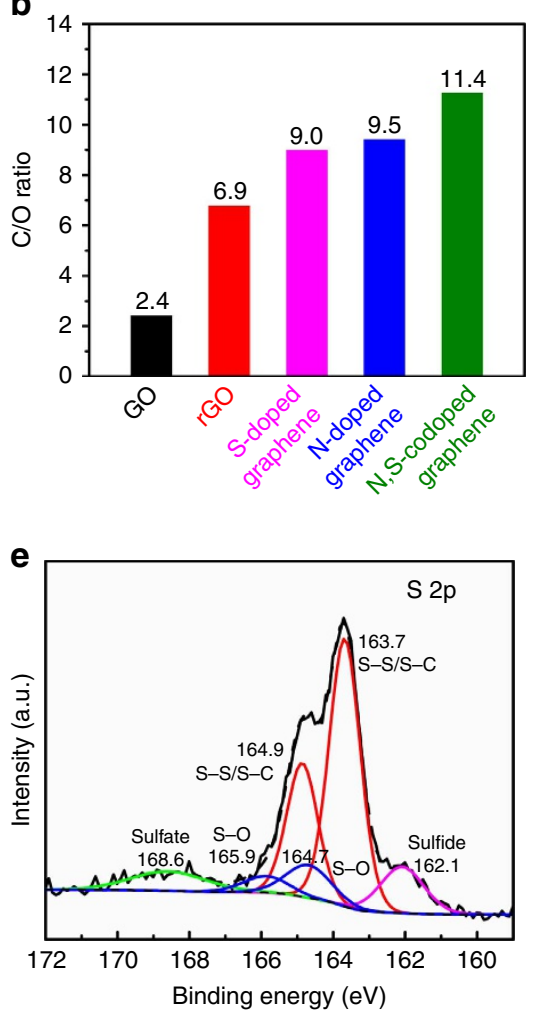

C

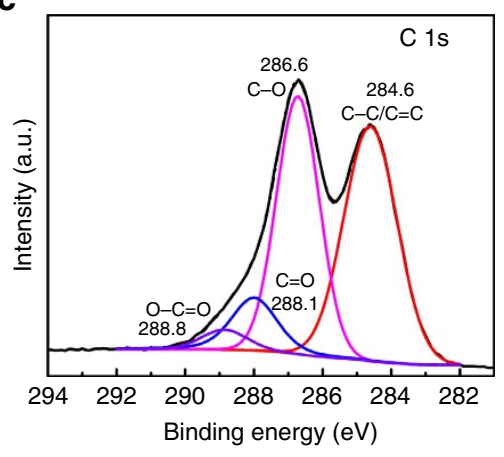

f

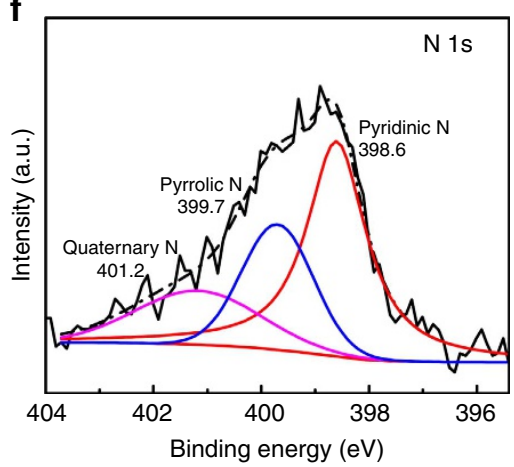

Figure 3 | Surface composition analysis. (a) XPS spectra of the surface chemical composition of GO, rGO, S-doped graphene, N-doped graphene and $\mathrm{N}, \mathrm{S}$-codoped graphene. (b) Relationship of the C/O ratio in the GO, rGO, S-doped graphene, N-doped graphene and N, S-codoped graphene. C 1s XPS spectra of the (c) GO and (d) N,S-codoped graphene. (e) S 2p XPS spectrum of the N,S-codoped graphene. (f) N 1s XPS spectrum of the N,S-codoped graphene. 
graphene and N,S-codoped graphene reach, respectively, 5.1 at.\% and 5.4 at.\%, and the sulphur contents are 0.6 at.\% and 3.9 at.\%, respectively, in S-doped graphene and $\mathrm{N}, \mathrm{S}$-codoped graphene, which further confirm that the $\mathrm{S}$ and/or $\mathrm{N}$ are incorporated into the carbon framework. GO shows a $\mathrm{C} / \mathrm{O}$ ratio of 2.4 and this value increases to 6.9 for rGO after the hydrothermal reaction, implying the partial reduction of GO (Fig. 3b). After the $\mathrm{S}, \mathrm{N}$ - and $\mathrm{N} / \mathrm{S}$-doping, the $\mathrm{C} / \mathrm{O}$ ratio further increases to, respectively, 9.0, 9.5 and 11.4, indicating a more efficient reduction during the doping process, which is consistent with the XRD and Raman results. The deconvoluted $\mathrm{C} 1 \mathrm{~s}$ spectra of GO show four peaks at $284.6 \mathrm{eV}, 286.6 \mathrm{eV}, 288.1 \mathrm{eV}$ and $288.8 \mathrm{eV}$ (Fig. 3c), respectively, corresponding to $\mathrm{C}-\mathrm{C} / \mathrm{C}=\mathrm{C}, \mathrm{C}-\mathrm{O}, \mathrm{C}=\mathrm{O}$ and $\mathrm{O}-\mathrm{C}=\mathrm{O}^{44}$. After the N,S-doping, these oxygen-containing groups decrease significantly, and the peak intensity corresponding to the $\mathrm{sp}^{2}$ carbon increases and becomes narrower (Fig. 3d), indicating the removal of oxygen-containing functional groups and the possible formation of C-S/C-N bonds during the reduction process ${ }^{22,45}$. The S 2p spectra of the N,S-codoped graphene can be deconvoluted into six peaks (Fig. 3e), which correspond to, respectively, sulphide at $162.1 \mathrm{eV}, \mathrm{S}-\mathrm{S} / \mathrm{S}-\mathrm{C}$ bonds at 163.7 and $164.9 \mathrm{eV}, \mathrm{S}-\mathrm{O}$ species at 164.7 and $165.9 \mathrm{eV}$, and sulfate species at $168.6 \mathrm{eV}$ (refs 20,36,45-47). In the N1s spectrum (Fig. 3f), the three different peaks at $398.6 \mathrm{eV}, 399.7 \mathrm{eV}$ and $401.2 \mathrm{eV}$ are ascribed to, respectively, pyridinic $\mathrm{N}$, pyrrolic $\mathrm{N}$ and quaternary $\mathrm{N}^{21,43}$. These functional groups are suggested to contribute to improving the affinity and binding energy of the nonpolar carbon atoms with polar polysulphides/ $\mathrm{Li}_{2} \mathrm{~S}$, thus significantly enhancing the cycle stability and rate capability of Li-S batteries ${ }^{19-21,36}$.

Adsorption capabilities and electrochemical performance. The polysulphide adsorption capabilities of these graphene-based sponges were investigated with ultraviolet-visible absorption spectroscopy. Pure $\mathrm{Li}_{2} \mathrm{~S}_{6}$ solution was used as a reference, the rGO, S-doped graphene, N-doped graphene and N,S-codoped graphene sponges were immersed into the $\mathrm{Li}_{2} \mathrm{~S}_{6}$ solution for $2 \mathrm{~h}$ and the concentration variation of $\mathrm{Li}_{2} \mathrm{~S}_{6}$ solution was analysed. The typical peaks of the polysulphide solution located at 260, 280, 300 and $340 \mathrm{~nm}$ (Supplementary Fig. 6) are attributed to the $\mathrm{S}_{6}^{2-}$ species $^{48-50}$. After the absorption for $2 \mathrm{~h}$, it can be clearly seen that the intensity decreases in these characteristic absorption peaks and the N,S-codoped graphene sponge exhibits the best adsorption capability compared with the rGO, S-doped graphene and $\mathrm{N}$-doped graphene sponges, demonstrating the improvement in affinity and adsorption between the $S_{6}^{2-}$ species and the graphene after the N,S functionalization.

To show whether the doped heteroatoms of $\mathrm{S}$ and/or $\mathrm{N}$ on the graphene have a positive effect on the performance of $\mathrm{Li}-\mathrm{S}$ batteries, these graphene sponges were cut into slices, compressed and directly used as free-standing electrodes for a series of electrochemical measurements. Different from two-dimensional graphene materials, 3D interconnected porous graphene sponges can provide multidimensional electron transport pathways and easily accessible active sites. Therefore, electrochemical impedance spectroscopy was used to analyse the kinetics of the electrochemical reactions. Figure $4 \mathrm{a}$ shows the Nyquist plots of the graphene-based sponge electrodes at the open-circuit voltage before cycling, and the equivalent circuit is shown in Supplementary Fig. 7. The high frequency intercept at the real axis corresponds to the internal impedance $\left(R_{\mathrm{e}}\right)$, and the semicircles located in the higher and lower frequency regions, respectively, correspond to the surface film resistance $\left(R_{\mathrm{f}}\right)$ and the charge-transfer resistance $\left(R_{\mathrm{ct}}\right)$ of the batteries ${ }^{51}$. The other elements in the equivalent circuit include a constant phase element (CPE) about the double-layer capacitance, Warburg impedance $\left(Z_{\mathrm{w}}\right)$ and space charge capacitance $\left(\mathrm{CPE}^{\prime}\right)^{52}$. From the plots, it can be seen that the rGO electrode has the largest internal resistance $(13.7 \Omega)$, while this resistance in the S-doped graphene $(5.5 \Omega)$, N-doped graphene (4.3 $\Omega$ ) and N,S-codoped graphene $(3.7 \Omega)$ electrodes are lower, which are in accordance with the results of the electrode electrical conductivity (Supplementary Fig. 5). The $R_{\mathrm{ct}}$ of the N,S-codoped graphene electrode is much smaller than those of the rGO, S-doped graphene and $\mathrm{N}$-doped graphene electrodes (Supplementary Table 3), which could be attributed to the interconnected porous graphene network and doped N/S atoms, facilitating the charge transfer for surface reactions ${ }^{21,22,36}$. Figure $4 \mathrm{~b}$ demonstrates the galvanostatic charge/ discharge profiles of the $\mathrm{Li} /$ dissolved polysulphide batteries with the rGO, S-doped graphene, N-doped graphene and N,S-codoped graphene electrodes at $0.2 \mathrm{C}$ rate $\left(1 \mathrm{C}=1,675 \mathrm{~mA} \mathrm{~g}^{-1}\right)$. Compared with the $\mathrm{rGO}$, S-doped graphene and $\mathrm{N}$-doped graphene electrodes, the discharge/charge profiles of the N,S-codoped graphene electrode have an obvious higher discharge plateau at $\sim 2.32 \mathrm{~V}$ (reduction of sulphur to long-chain lithium polysulphides) and a longer plateau at $\sim 2.10 \mathrm{~V}$ (formation of short-chain lithium polysulphides) with corresponding charge plateaus at $\sim 2.30$ and $\sim 2.45 \mathrm{~V}$ (transformation from $\mathrm{Li}_{2} \mathrm{~S}_{2} / \mathrm{Li}_{2} \mathrm{~S}$ to long-chain lithium polysulphides and then to sulphur) ${ }^{53}$. These plateaus are longer and flatter with lower polarization and are well-retained even at higher current densities of $0.3-2 \mathrm{C}$ rates between the charge/discharge processes when compared with those of $\mathrm{rGO}, \mathrm{S}$-doped graphene and $\mathrm{N}$-doped graphene electrodes (Fig. 4c and Supplementary Fig. 8), suggesting better redox reaction kinetics with good reversibility. For example, the overpotential is $809 \mathrm{mV}$ in the N,S-codoped graphene electrode at a high rate of $2 \mathrm{C}$, much lower than that of $\mathrm{rGO}$ electrode $(1,185 \mathrm{mV})$, S-doped graphene $(1,080 \mathrm{mV})$ and $\mathrm{N}$-doped graphene electrode $(1,010 \mathrm{mV})$.

The cycle performances of these electrodes were first tested at a small current density of $0.2 \mathrm{C}$ rate, as shown in Fig. $4 \mathrm{~d}$. The N,Scodoped graphene electrode delivers an initial discharge capacity of $1,200 \mathrm{mAh} \mathrm{g}^{-1}$, and the capacity is retained at $822 \mathrm{mAh} \mathrm{g}^{-1}$ after 100 cycles with nearly $100 \%$ Coulombic efficiency, which is much higher than that of the rGO, S-doped graphene and $\mathrm{N}$-doped graphene electrodes with values of $495 \mathrm{mAhg}^{-1}$, $646 \mathrm{mAhg}^{-1}$ and $705 \mathrm{mAhg}^{-1}$, respectively. Lithium nitrate $\left(\mathrm{LiNO}_{3}\right)$ is added to promote the formation of a stable passivation film, and the capacity decay at the initial few cycles is partially due to the $\mathrm{LiNO}_{3}$ decomposition and the formation of a SEI film on the lithium anode surface ${ }^{54,55}$. To further elucidate the electrochemical reactivity of doped sulphur in the graphene framework, the blank galvanostatic charge/discharge profiles and the cyclic stability of N,S-codoped graphene are shown in Supplementary Fig. 9. It can be seen that the first discharge capacity is $219 \mathrm{mAhg}^{-1}$, and the voltage plateau at $\sim 1.6 \mathrm{~V}$ is attributed to the reduction of $\mathrm{LiNO}_{3}$ on the carbon and lithium surface ${ }^{55}$. The capacity remains to be only $46 \mathrm{mAh} \mathrm{g}^{-1}$ after 100 cycles, demonstrating its little contribution to the overall capacity. To demonstrate the rate capabilities of these electrodes, the current density was changed from 0.2 to $2 \mathrm{C}$ rate, as shown in Fig. 4e. The average discharge capacities for the N,S-codoped graphene electrode at $0.2 \mathrm{C}, 0.5 \mathrm{C}, 1 \mathrm{C}$ and $2 \mathrm{C}$ rates are, respectively, $1,157 \mathrm{mAh} \mathrm{g}^{-1}, 912 \mathrm{mAh} \mathrm{g}^{-1}, 675 \mathrm{mAhg}^{-1}$ and $430 \mathrm{mAhg}^{-1}$, indicating a high charge/discharge capability. However, the rGO electrode shows almost no capacity at $2 \mathrm{C}$ rate, demonstrating poor rate performance. When the current density was reduced back to $0.5 \mathrm{C}$ rate, the discharge capacity can be recovered to $878 \mathrm{mAhg}^{-1}$ for the N,S-codoped graphene electrode, indicating that the electrode structure remains stable after the high-current-density test. Even after the rate capability 

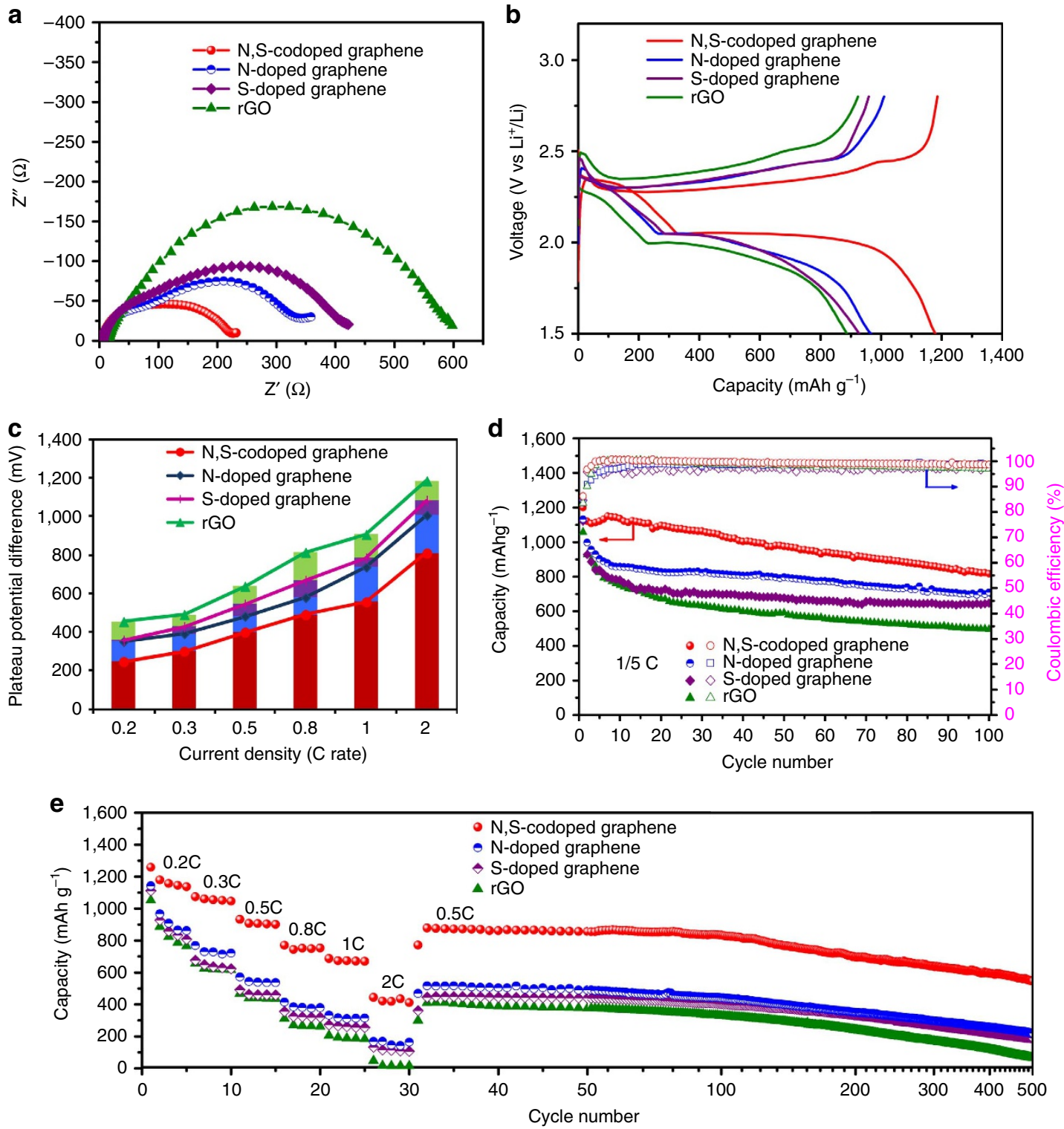

Figure 4 | Electrochemical performance of Li/polysulphide batteries with different graphene electrodes. (a) Nyquist plots of the rGO, S-doped graphene, $\mathrm{N}$-doped graphene and $\mathrm{N}, \mathrm{S}$-codoped graphene electrodes before cycling from $1 \mathrm{MHz}$ to $100 \mathrm{mHz}$ at room temperature. (b) The second galvanostatic charge/discharge profiles of the $\mathrm{rGO}, \mathrm{S}$-doped graphene, $\mathrm{N}$-doped graphene and $\mathrm{N}$, $\mathrm{S}$-codoped graphene electrodes at $0.2 \mathrm{C}$ rate within a potential window of $1.5-2.8 \mathrm{~V}$ versus $\mathrm{Li}^{+} / \mathrm{Li}^{0}$. (c) Comparison of the potential difference between the charge and discharge plateaus at different current densities. (d) Cycling performance and Coulombic efficiency of the Li polysulphide batteries with the rGO, S-doped graphene, N-doped graphene and N,Scodoped graphene electrodes at $0.2 \mathrm{C}$ rate for 100 cycles. (e) Rate performance of the rGO, S-doped graphene, N-doped graphene and N,S-codoped graphene electrodes at different current densities and long-term cycle stability of the corresponding electrodes at $0.5 \mathrm{C}$ for 500 cycles after the highcurrent-density test.

test, the N,S-codoped graphene electrode still shows excellent long-cyclic performance with higher capacity $\left(550 \mathrm{mAh}^{-1}\right)$ and retention (63\%) compared with the $\mathrm{rGO}\left(66 \mathrm{mAhg}^{-1}, 16 \%\right)$, S-doped graphene $\left(190 \mathrm{mAh} \mathrm{g}^{-1}, 42 \%\right)$ and $\mathrm{N}$-doped graphene $\left(221 \mathrm{mAhg}^{-1}, 43 \%\right)$ electrodes at a current density of $0.5 \mathrm{C}$ rate up to 500 cycles. The capacity decay is only $0.078 \%$ per cycle for the N,S-codoped graphene electrode, much better than those of the rGO, S-doped graphene and $\mathrm{N}$-doped graphene electrodes with decay rates of $0.179 \%, 0.124 \%$ and $0.121 \%$ per cycle, respectively. These results imply that the nitrogen- and sulphurdoped 3D porous graphene sponge could not only facilitate fast electron/ion transfer, but also interact strongly with lithium polysulphides to significantly enhance the rate performance and long-term cyclic stability.
To further improve the energy density of the whole battery system and satisfy the demands of high-energy batteries, the active material loading was increased from 4.6 to $8.5 \mathrm{mg} \mathrm{cm}^{-2}$ by adding more $\mathrm{Li}_{2} \mathrm{~S}_{6}$ catholyte into the N,S-codoped graphene electrode with the help of a graphene-coated separator, which has been confirmed as a very useful approach to obtain highperformance Li-S batteries ${ }^{56}$. From the charge/discharge curves of the N,S-codoped graphene electrodes with graphene-coated separator (Fig. 5a), it is obviously observed that two discharge/ charge plateaus are well-retained even at a high rate of $2 \mathrm{C}$, indicating that the reaction dynamic is not affected by high sulphur loading. Owing to the uniform distribution of liquidphase active materials, the polysulphides could be utilized effectively, thereby avoiding the phenomenon of 'sulphur 
a

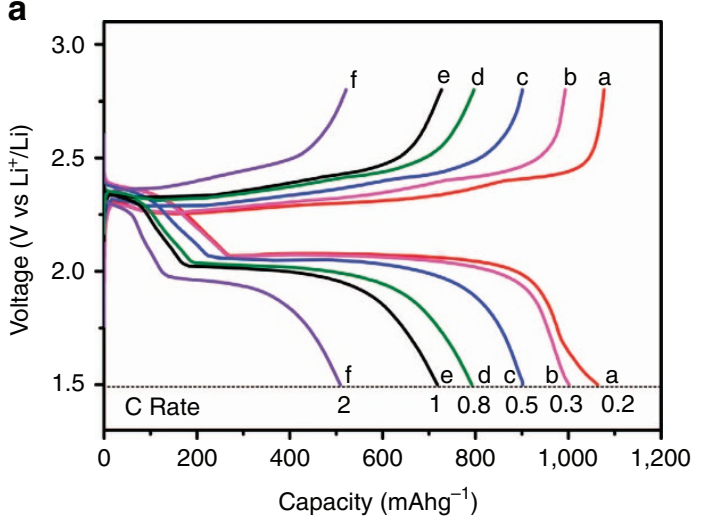

b

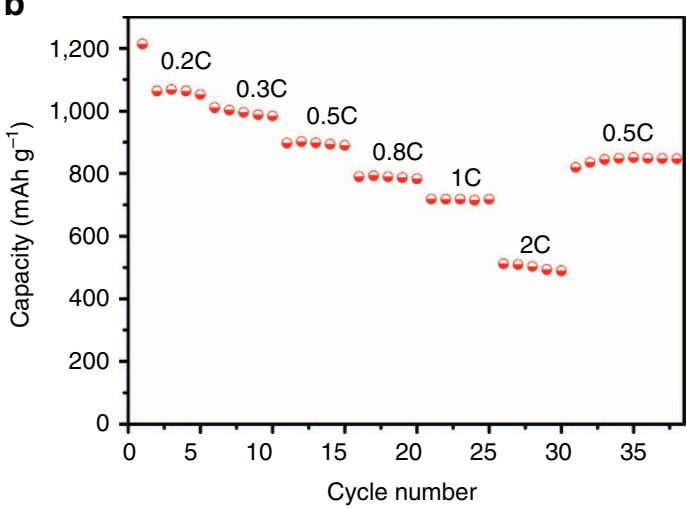

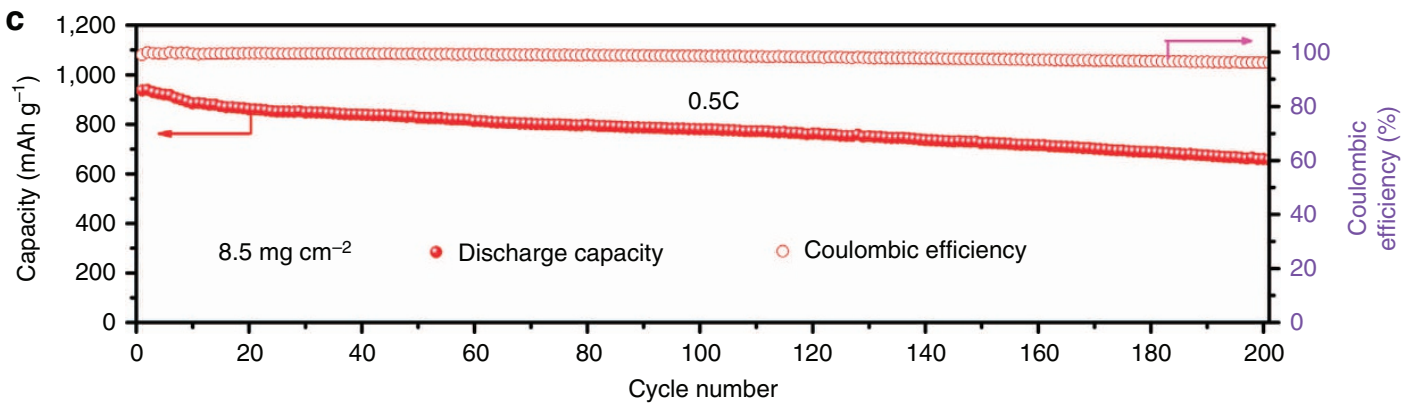

Figure 5 | Electrochemical measurement of N,S-codoped graphene electrode with graphene-coated separator. (a) Galvanostatic charge/discharge profiles of the N,S-codoped graphene electrode with graphene-coated separator at various rates within a potential window of $1.5-2.8 \mathrm{~V}$ versus $\mathrm{Li}^{+} / \mathrm{Li}^{0}$. (b) Rate performance of the N,S-codoped graphene electrode with graphene-coated separator at different current densities. (c) Cycling performance and Coulombic efficiency of the Li polysulphide batteries with the N,S-codoped graphene electrodes and graphene-coated separator at $0.5 \mathrm{C}$ rate for 200 cycles.

activation $28,29,31$. The unique structure enables the battery to deliver a high capacity of $1,070 \mathrm{mAhg}^{-1}$ at $0.2 \mathrm{C}$ rate, and the reversible discharge capacity could reach $c a .500 \mathrm{mAhg}^{-1}$ at a large current density of $2 \mathrm{C}$ rate (Fig. 5b). In addition, a long-term cyclic test at $0.5 \mathrm{C}$ rate was carried out and the initial specific capacity is $925 \mathrm{mAhg}^{-1}$, which stabilizes $\sim 670 \mathrm{mAhg}^{-1}$ after 200 cycles (Fig. 5c). The advantages of such electrode configuration design includes the following: (i) the graphene sponge functions as a 3D current collector to accommodate a large amount of active material, and the internal graphene layer further improves the polysulphide utilization due to the increased overall electrical conductivity of the system; (ii) the graphene layers effectively trap the dissolved lithium polysulphide and provide more active sites for $\mathrm{Li}_{2} \mathrm{~S}$ deposition; (iii) the $3 \mathrm{D}$ graphene network and graphene layer can accommodate the volume change of the active material during cycling; and (iv) the chemical binding between the sulphur/nitrogen heteroatoms and lithium polysulphide/ $\mathrm{Li}_{2} \mathrm{~S}$ reduces the active material loss, realizing long cycle life and high-energy/power density $\mathrm{Li}-\mathrm{S}$ batteries.

\section{Discussion}

To understand the structure and surface modification in improving the performance of N,S-codoped graphene electrode, the cells were disassembled inside the glove box and the surface morphology of the graphene-based sponge cathodes and the lithium metallic anodes after 100 cycles were observed by SEM. It can be seen that a thick layer of lithium sulphide $\left(\mathrm{Li}_{2} \mathrm{~S}\right)$ deposition is present on the surface of rGO and the corresponding metallic lithium surface is rough with many coarse lithium agglomerations (Supplementary Figs 10a and 11a), suggesting a serious parasitic reaction between dissolved lithium polysulphides and metallic lithium anode during cycling. This can also be confirmed from the corresponding sulphur elemental mapping characterization and EDS compositional analysis (Supplementary Fig. 11b, Supplementary Table 4). In contrast, less deposition is seen on the $\mathrm{S}$-doped graphene and $\mathrm{N}$-doped graphene electrodes (Supplementary Fig. 10b,c), and no obvious aggregations of sulphur species are observed on the N,S-codoped graphene electrode (Supplementary Fig. 10d), showing less dissolution loss of polysulphides into the electrolyte and their re-deposition on the S-doped, N-doped and N,S-codoped graphene electrodes. Correspondingly, the lithium surface of S-doped graphene, $\mathrm{N}$-doped graphene and N,S-codoped graphene electrodes is also smoother (Supplementary Fig. 11c,e,g) with respect to the rGO electrode, showing that less side reactions have occurred on the surface of metallic lithium, thereby alleviating the lithium surface corrosion and contributing to the improved cycling performance (Supplementary Fig. 11d,f,h and Supplementary Table 4).

To better understand the doping effect, density functional theory (DFT) calculations were performed to examine how the binding strength of the $\mathrm{Li}-\mathrm{S}$ end of linear lithium polysulphides $\left(\mathrm{Li}_{2} \mathrm{~S}_{x}\right)$ is influenced by the incorporation of $\mathrm{N}$ and/or $\mathrm{S}$ atoms into the graphene lattice. Here we used a small LiSH molecule to model the Li-S end. This model is simple but should be sufficient enough to demonstrate the influence of doping particularly on the binding interaction of the terminal $\mathrm{Li}^{+}$cation with a doped graphene sheet, although lithium polysulphides may also exist as complex clusters ${ }^{57-59}$. To confirm whether the $\mathrm{H}$-terminated S will influence the predicted binding strength of the terminal $\mathrm{Li}^{+}$, we also considered $\mathrm{Li}_{2} \mathrm{~S}$ adsorption at a few selected dopant sites, as shown in Supplementary Fig. 12. There are no significant binding energy differences between $\mathrm{Li}_{2} \mathrm{~S}$ and $\mathrm{LiSH}$, implying that it would be reasonable and feasible to use LiSH for the purpose of supporting our experimental observations. For a reference, we 
first considered the binding of LiSH to a pristine graphene sheet and a 1,3-dioxolane (DOL) molecule, which is widely used for the electrolyte in a $\mathrm{Li}-\mathrm{S}$ cell. As shown in Fig. $6 \mathrm{a}$, the $\mathrm{Li}$ of $\mathrm{LiSH}$ is preferentially located at the hollow site above the centre of a hexagon ring with a predicted binding energy of $E_{\mathrm{b}}=0.78 \mathrm{eV}$, in good agreement with the previous DFT results ${ }^{57}$. Here the $E_{\mathrm{b}}$ is given by $E_{\mathrm{LiSH}}+E_{\mathrm{Gr}}-E_{\mathrm{LiSH} / \mathrm{Gr}}$, where $E_{\mathrm{LiSH}}, E_{\mathrm{Gr}}$ and $E_{\mathrm{LiSH} / \mathrm{Gr}}$ represent the total energies of an isolated $\mathrm{LiSH}$, pristine (or doped) graphene and LiSH adsorbed graphene, respectively. Our calculations also predict that the $\mathrm{Li}$ of $\mathrm{LiSH}$ can be strongly bound to the $\mathrm{O}$ site of DOL with $E_{\mathrm{b}}=0.93 \mathrm{eV}$ (Fig. 6b); the larger $E_{\mathrm{b}}$ than that for the graphene case $(0.78 \mathrm{eV})$ may suggest that lithium polysulphides would dissolve into the DOL-based electrolyte instead of adsorbing on the graphene surface, consistent with the existing experimental observations ${ }^{10,47}$.

Next, we examined the interaction of LiSH with doped graphene. Figure 6 shows the adsorption configurations of LiSH at highly probable binding sites identified from our DFT calculations; (Fig. 6c-e) S doped, (Fig. 6f-h) $\mathrm{N}$ doped and (Fig. 6i-k) N,S codoped. Compared with the case of pristine graphene, the $E_{\mathrm{b}}$ is predicted to increase by $0.24 \mathrm{eV}$ at the thionic $\mathrm{S}$ site (Fig. 6c), but decrease by $0.26 \mathrm{eV}$ at the thiophenic $\mathrm{S}$ site (Fig. 6d). We also considered the interaction of $\mathrm{LiSH}$ with $\mathrm{S}$ placed on the basal plane of graphene (Fig. 6e), but the weakly bound $\mathrm{S}$ turns out to easily desorb off the graphene surface by forming $\mathrm{LiS}_{2} \mathrm{H}$. LiSH is also found to strongly interact with pyridinic and pyrrolic $\mathrm{N}$ at the edge of graphene (Fig. 6f,g); the predicted $E_{\mathrm{b}}$ of $1.29 \mathrm{eV}$ and $1.43 \mathrm{eV}$, respectively, are substantially greater than that of the pristine graphene case $(0.78 \mathrm{eV})$. On the other hand, the quaternary $\mathrm{N}$ doping (Fig. 6h) appears to insignificantly affect the LiSH binding strength, although the electron-rich surface due to electron donation from $\mathrm{N}$ likely leads to the increase in $E_{\mathrm{b}}$ to a certain extent. Overall, our results are consistent with the previously reported DFT results ${ }^{19,21,22}$. Looking at N,S-codoped graphene, our DFT calculations predict that thionic $\mathrm{S}$ can exist adjacent to pyridinic or pyrrolic $\mathrm{N}$, as shown in Fig. 6i,j; the total energy of the codoped graphene tends to increase (decrease) with the $\mathrm{S}-\mathrm{N}$ distance in the case of pyridinic (pyrrolic) $\mathrm{N}$, but only marginally $(<0.05 \mathrm{eV})$. When thionic $S$ and pyridinic (pyrrolic) $\mathrm{N}$ are located nearby, the binding strength of $\mathrm{LiSH}$ is predicted to increase significantly, yielding $E_{\mathrm{b}}=1.82(2.06) \mathrm{eV}$, as compared with the separately doped cases (Fig. 6f,g). In addition, we find that LiSH is likely to interact more strongly with thionic $\mathrm{S}$ in the quaternary $\mathrm{N}$-doped graphene (Fig. 6k), in comparison to the case of single doped graphene (Fig. 6c).

$\mathrm{N}$ and $\mathrm{S}$ atoms could be incorporated into graphene in various configurations, yielding a wide range of $E_{\mathrm{b}}$; a few additional cases a

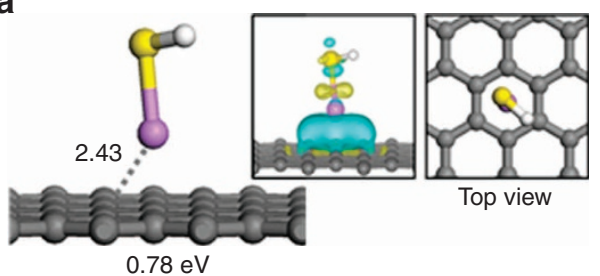

b

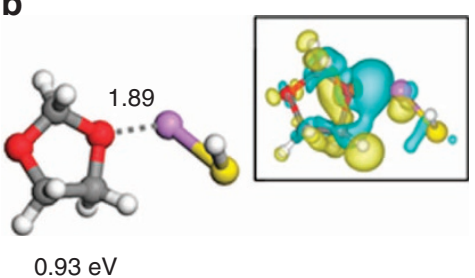

e

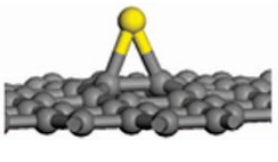

h

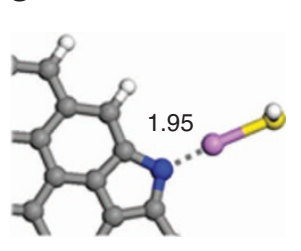

$1.43 \mathrm{eV}$

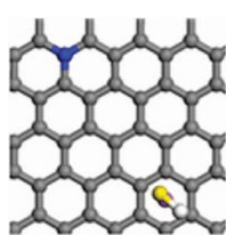

$0.82 \mathrm{eV}$

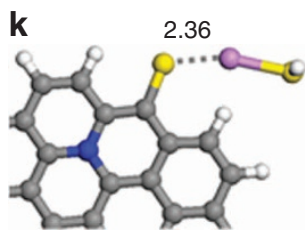

$1.10 \mathrm{eV}$

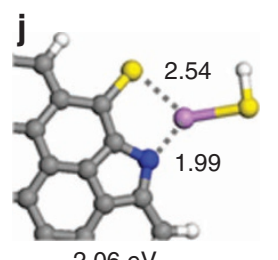

Figure 6 | Theoretical calculations. Optimized configurations for the binding of LiSH to (a) pristine graphene, (b) 1,3-dioxolane, (c-e) S-doped graphene, (f-h) N-doped graphene and (i-k) N,S-codoped graphene. Charge density difference isosurfaces are shown in the insets; the blue and yellow colours indicate the regions of charge gain and loss (of \pm 0.001 e per bohr ${ }^{3}$ ), respectively. Grey, white, blue, yellow, purple and red balls represent $\mathrm{C}, \mathrm{H}, \mathrm{N}, \mathrm{S}, \mathrm{Li}$ and $\mathrm{O}$ atoms, respectively. LiSH binding energies (in $\mathrm{eV}$ ) and selected bond distances (in $\AA$ ) are also indicated. 
are presented in Supplementary Fig. 13. Nonetheless, our DFT results clearly demonstrate that the coexistence of $\mathrm{N}$ and $\mathrm{S}$ can significantly enhance the binding of lithium polysulphides, when compared with the undoped or single N/S-doping cases. In addition, according to our calculations, thionic $S$ and pyridinic (or pyrrolic) $\mathrm{N}$ could exist adjacent to each other at graphene edges and vacancies, which may in turn lead to an increase in the amount of dopants, when $\mathrm{N}$ and $\mathrm{S}$ are codoped as compared with the cases of single $\mathrm{N}$ (or S)-doping. Overall, our theoretical findings regarding the synergistic effect of N,S-codoping wellsupport our experimental observations.

In summary, we have built a strong bound interface between graphene and soluble lithium polysulphides by N,S-codoping to optimize the electrochemical performance towards stable and high-energy density Li-S batteries. The N,S-codoped graphene conductive framework provides high electrical conductivity, strong adsorption abilities for polysulphides and rapid ontransport channels, and works as a 3D scaffold to accommodate high active material loading. As a result, the N,S-codoped graphene electrode with a high sulphur loading of $4.6 \mathrm{mg} \mathrm{cm}^{-2}$ exhibits fast reaction dynamics, reduced polarization and stabilized cycling performance with only $0.078 \%$ capacity decay per cycle up to 500 cycles. In addition, the sulphur loading could be further increased to $8.5 \mathrm{mg} \mathrm{cm}^{-2}$ using the 3D N,S-codoped graphene current collector with the help of a graphene-coated separator. The high loading polysulphides could be effectively utilized with high reversibility and excellent stability. This work demonstrates the great potential of using $3 \mathrm{D}$ current collector and surface chemical modifications for high-energy density, long-life energy storage devices.

\section{Methods}

Synthesis of GO. GO was synthesized using natural graphite flakes by a modified Hummers' method ${ }^{60}$. The concentration of the GO suspension obtained was $2.6 \mathrm{mg} \mathrm{ml}^{-1}$, which was determined by freeze-drying the suspension and weighing the dried GO.

Synthesis of rGO sponge. Hydrothermal assembly and freeze-drying process were combined to fabricate rGO sponge. In a typical procedure, $50 \mathrm{ml}$ of GO suspension was transferred into a $100 \mathrm{ml}$ Teflon-lined stainless steel autoclave and hydrothermally treated at $180^{\circ} \mathrm{C}$ for $12 \mathrm{~h}$. Then the autoclave was naturally cooled to room temperature, the black rGO hydrogel was washed with distilled water and the wet hydrogel was freeze-dried to obtain the rGO sponge.

Synthesis of S-doped graphene sponge. About $0.01 \mathrm{~mol}$ of $\mathrm{Na}_{2} \mathrm{~S}$ was added to $50 \mathrm{ml}$ of distilled water and the above obtained rGO hydrogel was then transferred into the solution, sealed in the autoclave and maintained at $180^{\circ} \mathrm{C}$ for $12 \mathrm{~h}$. After that, the S-doped graphene hydrogel was dipped into distilled water and washed several times to remove the residual salts and freeze-dried to obtain the S-doped graphene sponge.

Synthesis of $\mathbf{N}$-doped graphene sponge. About $0.01 \mathrm{~mol}$ of urea was added to $50 \mathrm{ml}$ of distilled water and stirred magnetically for $30 \mathrm{~min}$. The obtained rGO hydrogel was then transferred into the solution and sealed in the autoclave and maintained at $180^{\circ} \mathrm{C}$ for $12 \mathrm{~h}$. After that, the $\mathrm{N}$-doped graphene hydrogel was dipped into distilled water and washed several times to remove the residual urea and freeze-dried to obtain the $\mathrm{N}$-doped graphene sponge.

Synthesis of N,S-codoped graphene sponge. In brief, $50 \mathrm{ml}$ of the GO aqueous dispersion and $0.01 \mathrm{~mol}$ of thiourea were mixed and the mixture was stirred for $30 \mathrm{~min}$ and sealed in a $100 \mathrm{ml}$ Teflon-lined stainless steel autoclave for hydrothermal reaction at $180^{\circ} \mathrm{C}$ for $12 \mathrm{~h}$. Then the black hydrogel was washed with distilled water several times to remove the residual thiourea and freeze-dried to obtain the N,S-codoped graphene sponge.

Materials characterization. SEM observations were carried out on a FEI Quanta 650 SEM operated at $20 \mathrm{kV}$. STEM was performed with a Hitachi S-5500 SEM, and EDS was used for collecting elemental signals and mapping. XRD patterns were collected with a Philips X-ray diffractometer with $\mathrm{Cu} \mathrm{K} \alpha$ radiation $(\lambda=0.154056$ $\mathrm{nm}$ ) between $10^{\circ}$ and $70^{\circ}$ at a scan rate of $0.04^{\circ} \mathrm{s}^{-1}$. Raman spectra were collected with a $488 \mathrm{~nm}$ laser under ambient conditions with a WITEC Alpha300 S micro-
Raman system at room temperature. XPS analysis was performed on a Kratos Analytical spectrometer at room temperature with monochromatic AlK $\alpha$ $(1,486.6 \mathrm{eV})$ radiation. Ultraviolet-visible absorption spectroscopy analysis was performed to evaluate the polysulphide adsorption capability of rGO, S-doped graphene, $\mathrm{N}$-doped graphene and N,S-codoped graphene sponges. About $4 \mathrm{mg}$ each of rGO, S-doped graphene, $\mathrm{N}$-doped graphene and N,S-codoped graphene sponges were separately added into four sealed vials of $\mathrm{Li}_{2} \mathrm{~S}_{6}$ solution $(4 \mathrm{ml}$ each, $\left.0.1 \mathrm{mmoll}^{-1}\right)$, and the $\mathrm{Li}_{2} \mathrm{~S}_{6}$ solution without adding anything was used as a control. After absorption for $2 \mathrm{~h}$, the ultraviolet-visible absorption spectra of these solutions were collected with an Evolution 300 UV-vis spectrophotometer with baseline correction. The electrical conductivity of the electrodes was measured by a standard four-point probe resistivity measurement system (S-302-4, Lucas Labs Resistivity, USA). Three measurements were taken at different positions on the sample, and the average value was taken.

Preparation of electrolyte and polysulphide catholyte. The blank electrolyte was prepared by dissolving an appropriate amount of lithium trifluoromethanesulfonate $\left(\mathrm{LiCF}_{3} \mathrm{SO}_{3}, 98 \%\right.$, Acros Organics, $\left.1 \mathrm{M}\right)$ and $\mathrm{LiNO}_{3}$ $(99+\%$, Acros Organics, $0.1 \mathrm{M})$ in DME $(99+\%$, Acros Organics) and DOL (99.5\%, Acros Organics) (1:1 by volume). The polysulphide catholyte was prepared by chemically reacting sublimed sulphur (99.5\%, Fisher Scientific) and an appropriate amount of $\mathrm{Li}_{2} \mathrm{~S}$ (99.9\%, Acros Organics) in the blank electrolyte to form $\mathrm{Li}_{2} \mathrm{~S}_{6}(1.0 \mathrm{M})$ in the solution. The solution was then stirred at $50^{\circ} \mathrm{C}$ in an $\mathrm{Ar}$-filled glove box overnight to produce a brownish-red $\mathrm{Li}_{2} \mathrm{~S}_{6}$ catholyte solution.

Electrochemical measurements. The Li/dissolved polysulphide cells (CR2032 coin cells) were assembled in an Ar-filled glove box. The rGO, S-doped graphene, $\mathrm{N}$-doped graphene and $\mathrm{N}, \mathrm{S}$-codoped graphene sponges were dried at $120^{\circ} \mathrm{C}$ under vacuum overnight before using. These samples were cut, compressed and shaped into rectangular plates to be used as the current collectors with an area of $0.5 \mathrm{~cm}^{2}$ and a mass of $0.9-1.4 \mathrm{mg}$. About $12 \mu \mathrm{l}$ of $\mathrm{Li}_{2} \mathrm{~S}_{6}$ catholyte $(1.0 \mathrm{M})$ was added into each of the rGO, S-doped graphene, $\mathrm{N}$-doped graphene and $\mathrm{N}, \mathrm{S}$-codoped graphene electrodes, corresponding to a sulphur loading of $4.6 \mathrm{mg} \mathrm{cm}^{-2}$. The Celgard 2500 separator was then placed on top of the electrode, followed by adding $30 \mu \mathrm{l}$ of the blank electrolyte. Finally, the lithium-metal foil anode was placed on the separator as the anode. An Arbin battery cycler was used to perform the galvanostatic cycling measurements at $1.5-2.8 \mathrm{~V}$ (versus $\mathrm{Li}^{2} \mathrm{Li}^{+}$) at room temperature. The current density set for tests was referred to the mass of sulphur in the cathode and was varied from $0.2 \mathrm{C}$ to $2 \mathrm{C}$ rate. For the high sulphur loading cathode, $22 \mu \mathrm{l}$ of $\mathrm{Li}_{2} \mathrm{~S}_{6}$ catholyte $(1.0 \mathrm{M})$ was added into the N,S-codoped graphene electrodes, corresponding to a sulphur loading of $8.5 \mathrm{mg} \mathrm{cm}^{-2}$. The graphene-coated separator was used to place on the top of the sulphur cathode followed by adding $50 \mu \mathrm{l}$ of the blank electrolyte. Electrochemical impedance spectroscopy measurements were performed with a Solartron Impedance Analyzer (Solartron 1260A) in the frequency range of $1 \mathrm{MHz}$ to $0.1 \mathrm{~Hz}$ with an $\mathrm{AC}$ voltage amplitude of $5 \mathrm{mV}$ at the open-circuit potential. For the cycled samples, the cycled cells were disassembled inside an Ar-filled glove box, and the electrodes were rinsed with 1,2-dimethoxyethane solvent to remove the lithium salt and dried inside the glove box at room temperature before analysis.

Theoretical calculations. The atomic configurations and binding energies reported herein were calculated using DFT within the Perdew-Berke-Ernzerhof generalized gradient approximation (GGA-PBE) ${ }^{61}$, as implemented in the Vienna $A b$ initio Simulation Package (VASP) ${ }^{62}$. We employed the projector augmented wave method to describe the interaction between ion core and valence electrons and a plane-wave basis set with a kinetic energy cutoff of $400 \mathrm{eV}$. A graphene sheet was modelled using a hexagonal $7 \times 7$ supercell; we used the GGA-optimized lattice constant of $2.466 \AA$, which is close to the experimental value of $2.46 \AA$. Periodic boundary conditions were employed in all three directions with a vacuum gap of $15 \AA$ in the vertical $(z)$ direction to avoid interactions between graphene and its periodic images. To model $\mathrm{N}$ and/or $\mathrm{S}$ dopant atoms at graphene edges and vacancies, we employed a graphene flake consisting of $37 \mathrm{C}$ atoms in a periodic simulation box of dimensions $20 \times 20 \times 15 \AA$; dangling $\mathrm{C}$ bonds were passivated by $\mathrm{H}$ atoms. A gamma-centred $2 \times 2 \times 1$ Monkhorst-Pack mesh of $\mathrm{k}$ points was used for the Brillouin zone integration. All atoms were fully relaxed until the residual forces on constituent atoms became smaller than $0.02 \mathrm{eV}^{-1}$. We used the semiempirical approach proposed by Grimme ${ }^{63}$ to take into account the vdW interactions within DFT.

\section{References}

1. Tarascon, J. M. \& Armand, M. Issues and challenges facing rechargeable lithium batteries. Nature 414, 359-367 (2001).

2. Dunn, B., Kamath, H. \& Tarascon, J.-M. Electrical energy storage for the grid: a battery of choices. Science 334, 928-935 (2011).

3. Bruce, P. G., Freunberger, S. A., Hardwick, L. J. \& Tarascon, J.-M. Li-O 2 and Li-S batteries with high energy storage. Nat. Mater. 11, 19-29 (2012).

4. Yang, Y., Zheng, G. \& Cui, Y. Nanostructured sulfur cathodes. Chem. Soc. Rev. 42, 3018-3032 (2013). 
5. Manthiram, A., Fu, Y., Chung, S.-H., Zu, C. \& Su, Y.-S. Rechargeable lithiumsulfur batteries. Chem. Rev. 114, 11751-11787 (2014).

6. Liang, Z. et al. Sulfur cathodes with hydrogen reduced titanium dioxide inverse opal structure. ACS Nano 8, 5249-5256 (2014).

7. Manthiram, A., Fu, Y. \& Su, Y.-S. Challenges and prospects of lithium-sulfur batteries. Acc. Chem. Res. 46, 1125-1134 (2012).

8. Wang, D.-W. et al. Carbon-sulfur composites for Li-S batteries: status and prospects. J. Mater. Chem. A 1, 9382-9394 (2013).

9. Zhang, Q., Cheng, X. B., Huang, J. Q., Peng, H. J. \& Wei, F. Review of carbon materials for advanced lithium-sulfur batteries. New Carbon Mater. 29, 241-264 (2014)

10. Ji, X. L., Lee, K. T. \& Nazar, L. F. A highly ordered nanostructured carbonsulphur cathode for Lithium-sulphur batteries. Nat. Mater. 8, 500-506 (2009).

11. Zheng, G. et al. Amphiphilic surface modification of hollow carbon nanofibers for improved cycle life of lithium sulfur batteries. Nano Lett. 13, 1265-1270 (2013).

12. Yin, Y. X., Xin, S., Guo, Y. G. \& Wan, L. J. Lithium-sulfur batteries: electrochemistry, materials, and prospects. Angew. Chem. Int. Ed. 52, 13186-13200 (2013).

13. Lv, W. et al. Tailoring microstructure of graphene-based membrane by controlled removal of trapped water inspired by the phase diagram. Adv. Funct. Mater. 24, 3456-3463 (2014).

14. Li, Z. et al. Insight into the electrode mechanism in lithium-sulfur batteries with ordered microporous carbon confined sulfur as the cathode. Adv. Energy Mater. 4, 1301473 (2014).

15. Seh, Z. et al. Sulphur- $\mathrm{TiO}_{2}$ yolk-shell nanoarchitecture with internal void space for long-cycle lithium-sulphur batteries. Nat. Commun. 4, 1331 (2013).

16. Zhou, W., Xiao, X., Cai, M. \& Yang, L. Polydopamine-coated, nitrogen-doped, hollow carbon-sulfur double-layered core-shell structure for improving lithium-sulfur batteries. Nano Lett. 14, 5250-5256 (2014).

17. Lin, Z., Liu, Z., Fu, W., Dudney, N. J. \& Liang, C. Phosphorous pentasulfide as a novel additive for high-performance lithium-sulfur batteries. Adv. Funct. Mater. 23, 1064-1069 (2013).

18. Ding, F. et al. Dendrite-free lithium deposition via self-healing electrostatic shield mechanism. J. Am. Chem. Soc. 135, 4450-4456 (2013).

19. Song, J. et al. Nitrogen-doped mesoporous carbon promoted chemical adsorption of sulfur and fabrication of high-areal-capacity sulfur cathode with exceptional cycling stability for lithium-sulfur batteries. Adv. Funct. Mater. 24, 1243-1250 (2014).

20. Zhou, G. M. et al. Fibrous hybrid of graphene and sulfur nanocrystals for highperformance lithium-sulfur batteries. ACS Nano 7, 5367-5375 (2013).

21. Peng, H.-J. et al. Strongly coupled interfaces between a heterogeneous carbon host and a sulfur-containing guest for highly stable lithium-sulfur batteries: mechanistic insight into capacity degradation. Adv. Mater. Interfaces 1, 1400227 (2014).

22. Wang, Z. et al. Enhancing lithium-sulphur battery performance by strongly binding the discharge products on amino-functionalized reduced graphene oxide. Nat. Commun. 5, 5002 (2014).

23. Hagen, M. et al. Development and costs calculation of lithium-sulfur cells with high sulfur load and binder free electrodes. J. Power Sources 224, 260-268 (2013).

24. Gao, J. \& Abruña, H. D. Key parameters governing the energy density of rechargeable Li/S batteries. J. Phys. Chem. Lett. 5, 882-885 (2014).

25. Qie, L. \& Manthiram, A. A facile layer-by-layer approach for high-arealcapacity sulfur cathodes. Adv. Mater. 27, 1694-1700 (2015).

26. Hu, L. et al. Lithium-ion textile batteries with large areal mass loading. $A d v$. Energy Mater. 1, 1012-1017 (2011).

27. Mazouzi, D. et al. Very high surface capacity observed using Si negative electrodes embedded in copper foam as 3D current collectors. Adv. Energy Mater. 4, 1301718 (2014).

28. Miao, L., Wang, W., Yuan, K., Yang, Y. \& Wang, A. A lithium-sulfur cathode with high sulfur loading and high capacity per area: a binder-free carbon fiber cloth-sulfur material. Chem. Commun. 50, 13231-13234 (2014).

29. Lu, S., Chen, Y., Wu, X., Wang, Z. \& Li, Y. Three-dimensional sulfur/graphene multifunctional hybrid sponges for lithium-sulfur batteries with large areal mass loading. Sci. Rep. 4, 4629 (2014)

30. Yuan, Z. et al. Hierarchical free-standing carbon-nanotube paper electrodes with ultrahigh sulfur-loading for lithium-sulfur batteries. Adv. Funct. Mater. 24, 6105-6112 (2014).

31. Zhou, G. M. et al. A graphene foam electrode with high sulfur loading for flexible and high energy Li-S batteries. Nano Energy 11, 356-365 (2015).

32. Fu, Y., Su, Y.-S. \& Manthiram, A. Highly reversible lithium/dissolved polysulfide batteries with carbon nanotube electrodes. Angew. Chem. Int. Ed. 52, 6930-6935 (2013).

33. Yang, Y., Zheng, G. \& Cui, Y. A membrane-free lithium/polysulfide semi-liquid battery for large-scale energy storage. Energy Environ. Sci. 6, 1552-1558 (2013).

34. Pu, X., Yang, G. \& Yu, C. Liquid-type cathode enabled by 3D sponge-like carbon nanotubes for high energy density and long cycling life of $\mathrm{Li}-\mathrm{S}$ batteries. Adv. Mater. 26, 7456-7461 (2014)
35. Chung, S.-H. \& Manthiram, A. Carbonized eggshell membrane as a natural polysulfide reservoir for highly reversible Li-S batteries. Adv. Mater. 26, 1360-1365 (2014).

36. See, K. A. et al. Sulfur-functionalized mesoporous carbons as sulfur hosts in Li-S Batteries: increasing the affinity of polysulfide intermediates to enhance performance. ACS Appl. Mater. Interfaces 6, 10908-10916 (2014)

37. Bai, H., Li, C., Wang, X. \& Shi, G. A pH-sensitive graphene oxide composite hydrogel. Chem. Commun. 46, 2376-2378 (2010).

38. Shin, Y.-E. et al. An ice-templated, pH-tunable self-assembly route to hierarchically porous graphene nanoscroll networks. Nanoscale 6, 9734-9741 (2014).

39. Wang, D. W., Li, F., Liu, M., Lu, G. Q. \& Cheng, H. M. 3D aperiodic hierarchical porous graphitic carbon material for high-rate electrochemical capacitive energy storage. Angew. Chem. Int. Ed. 47, 373-376 (2008).

40. Li, L. et al. Monolithic $\mathrm{Fe}_{2} \mathrm{O}_{3}$ /graphene hybrid for highly efficient lithium storage and arsenic removal. Carbon 67, 500-507 (2014).

41. Pei, S. \& Cheng, H.-M. The reduction of graphene oxide. Carbon $\mathbf{5 0}$ 3210-3228 (2012).

42. Wang, S. Y. et al. BCN graphene as efficient metal-free electrocatalyst for the oxygen reduction reaction. Angew. Chem. Int. Ed. 51, 4209-4212 (2012).

43. Wu, Z.-S. et al. Three-dimensional nitrogen and boron co-doped graphene for high-performance all-solid-state supercapacitors. Adv. Mater. 24, 5130-5135 (2012).

44. Stankovich, S. et al. Synthesis of graphene-based nanosheets via chemical reduction of exfoliated graphite oxide. Carbon 45, 1558-1565 (2007).

45. Zhao, J., Ren, W. \& Cheng, H.-M. Graphene sponge for efficient and repeatable adsorption and desorption of water contaminations. J. Mater. Chem. 22, 20197-20202 (2012).

46. Demir-Cakan, R. et al. Cathode composites for Li-S batteries via the use of oxygenated porous architectures. J. Am. Chem. Soc. 133, 16154-16160 (2011)

47. Ji, L. W. et al. Graphene oxide as a sulfur immobilizer in high performance lithium/sulfur cells. J. Am. Chem. Soc. 133, 18522-18525 (2011).

48. Barchasz, C. et al. Lithium/sulfur cell discharge mechanism: an original approach for intermediate species identification. Anal. Chem. 84, 3973-3980 (2012).

49. Han, K. et al. Free-standing nitrogen-doped graphene paper as electrodes for high-performance lithium/dissolved polysulfide batteries. ChemSusChem 7, 2545-2553 (2014).

50. Zhou, G. M., Zhao, Y., Zu, C. \& Manthiram, A. Free-standing $\mathrm{TiO}_{2}$ nanowire embedded graphene hybrid membrane for advanced Li/dissolved polysulfide batteries. Nano Energy 12, 240-249 (2015).

51. Zu, C. X., Su, Y. S., Fu, Y. Z. \& Manthiram, A. Improved lithium-sulfur cells with a treated carbon paper interlayer. Phys. Chem. Chem. Phys. 15, 2291-2297 (2013).

52. Yuan, L., Qiu, X., Chen, L. \& Zhu, W. New insight into the discharge process of sulfur cathode by electrochemical impedance spectroscopy. J. Power Sources 189, 127-132 (2009).

53. Xiao, L. F. et al. A soft approach to encapsulate sulfur: polyaniline nanotubes for lithium-sulfur batteries with long cycle life. Adv. Mater. 24, 1176-1181 (2012).

54. Aurbach, D. et al. On the surface chemical aspects of very high energy density, rechargeable Li-Sulfur batteries. J. Electrochem. Soc. 156, A694-A702 (2009).

55. Zhang, S. S. Role of $\mathrm{LiNO}_{3}$ in rechargeable lithium/sulfur battery. Electrochim. Acta 70, 344-348 (2012).

56. Zhou, G. M. et al. A graphene-pure-sulfur sandwich structure for ultrafast, long-life lithium-sulfur batteries. Adv. Mater. 26, 625-631 (2014).

57. Wang, B., Alhassan, S. M. \& Pantelides, S. T. Formation of large polysulfide complexes during the lithium-sulfur battery discharge. Phys. Rev. Appl. 2, 034004 (2014).

58. Assary, R. S., Curtiss, L. A. \& Moore, J. S. Toward a molecular understanding of energetics in Li-S batteries using nonaqueous electrolytes: a high-level quantum chemical study. J. Phys. Chem. C 118, 11545-11558 (2014).

59. Wang, L. et al. A quantum-chemical study on the discharge reaction mechanism of lithium-sulfur batteries. J. Energy Chem. 22, 72-77 (2013).

60. Zhao, J., Pei, S., Ren, W., Gao, L. \& Cheng, H.-M. Efficient preparation of largearea graphene oxide sheets for transparent conductive films. ACS Nano 4, 5245-5252 (2010).

61. Perdew, J. P., Burke, K. \& Ernzerhof, M. Generalized gradient approximation made simple. Phys. Rev. Lett. 77, 3865-3868 (1996).

62. Kresse, G. \& Furthmüller, J. VASP: the Guide. Vienna University of Technology (2001).

63. Grimme, S. Semiempirical GGA-type density functional constructed with a long-range dispersion correction. J. Comput. Chem. 27, 1787-1799 (2006).

\section{Acknowledgements}

This work was funded in part by the Advanced Research Projects Agency-Energy (ARPA-E), US Department of Energy, under Award Number DE-AR0000377. G.S.H. also gratefully acknowledges the Robert A. Welch foundation (F-1535) for partial 
financial support of the computational work and the Texas Advanced Computing Center (TACC) for providing HPC resources.

\section{Author contributions}

G.Z. designed and conducted the experiments and wrote the manuscript. E.P. performed the theoretical calculations and wrote the manuscript. A.M. and G.S.H. conceived and supervised this research and contributed to the manuscript. All authors discussed the results and commented on the manuscript.

\section{Additional information}

Supplementary Information accompanies this paper at http://www.nature.com/ naturecommunications

Competing financial interests: The authors declare no competing financial interests.
Reprints and permission information is available online at http://npg.nature.com/ reprintsandpermissions/

How to cite this article: Zhou, G. et al. Long-life Li/polysulphide batteries with high sulphur loading enabled by lightweight three-dimensional nitrogen/sulphur codoped graphene sponge. Nat. Commun. 6:7760 doi: 10.1038/ncomms8760 (2015).

\section{(c) (1)}

This work is licensed under a Creative Commons Attribution 4.0 International License. The images or other third party material in this article are included in the article's Creative Commons license, unless indicated otherwise in the credit line; if the material is not included under the Creative Commons license, users will need to obtain permission from the license holder to reproduce the material. To view a copy of this license, visit http://creativecommons.org/licenses/by/4.0/ 